CrossMark

\& click for updates

Cite this: RSC Adv., 2015, 5, 26726

DOI: $10.1039 / c 5 r a 90022 k$

www.rsc.org/advances

\section{Correction: Au@UiO-66: a base free oxidation catalyst}

K. Leus, ${ }^{a}$ P. Concepcion, ${ }^{b}$ M. Vandichel, ${ }^{c}$ M. Meledina, ${ }^{d}$ A. Grirrane, ${ }^{b}$ D. Esquivel, ${ }^{a}$ S. Turner, ${ }^{d}$ D. Poelman, ${ }^{e}$ M. Waroquier, ${ }^{c}$ V. Van Speybroeck, ${ }^{c}$ G. Van Tendeloo, ${ }^{d}$

H. García ${ }^{b}$ and P. Van Der Voort ${ }^{\star a}$

Correction for 'AuQUiO-66: a base free oxidation catalyst' by K. Leus et al., RSC Adv., 2015, 5, 22334-22342.

The authors apologise for the errors in the XPS spectra of Au@UiO-66- $\mathrm{NaBH}_{4}$ after catalysis. The correct Figure 8 is shown below:

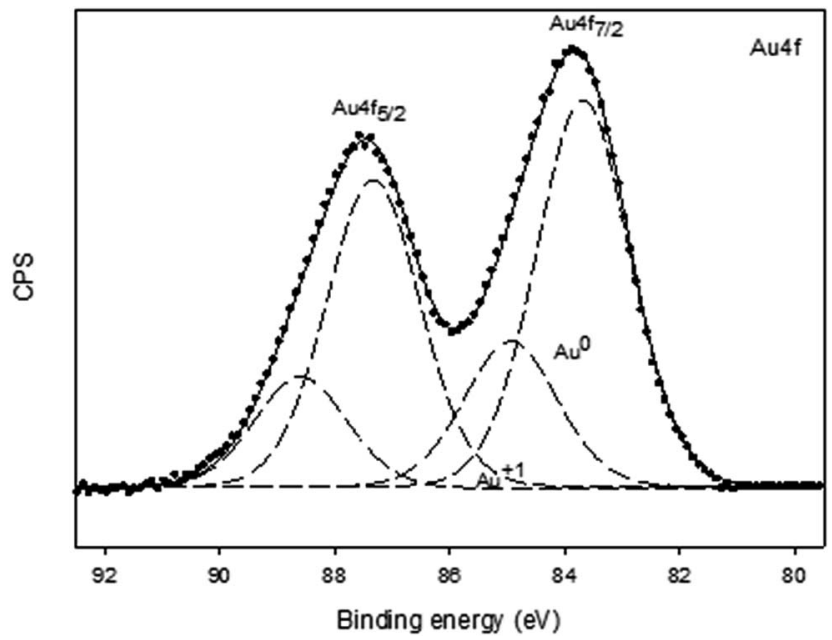

Fig. 8 XPS spectra in the $\mathrm{Au} 4 \mathrm{f}$ region of AuQUiO-66- $\mathrm{NaBH}_{4}$ after catalysis.

The Royal Society of Chemistry apologises for these errors and any consequent inconvenience to authors and readers.

${ }^{a}$ Department of Inorganic and Physical Chemistry, Center for Ordered Materials, Organometallics and Catalysis (COMOC), Ghent University, Krijgslaan 281-S3, 9000 Ghent, Belgium. E-mail: pascal.VanDerVoort@ugent.be

${ }^{b} I n s t i t u t o$ de Tecnología Química, CSIC-UPV, Universidad Politécnica de Valencia, Av. de los Naranjos s/n, 46022 Valencia, Spain

${ }^{c}$ Center for Molecular Modeling, Ghent University, Technologiepark 903, 9052 Zwijnaarde, Belgium

${ }^{d}$ Electron Microscopy for Materials Science (EMAT), University of Antwerp, Groenenborgerlaan 171, 2020 Antwerp, Belgium

${ }^{e}$ Department of Solid State Sciences, Lumilab, Ghent University, Krijgslaan 281-S1, 9000 Ghent, Belgium 